\title{
OTORITARIANISME ULAMA (Analisis atas MUI dengan Pemikiran Khaled Abou El Fadhl)
}

\author{
Agus Purnomo \\ STAIN Ponorogo \\ E-mail: Agus-chalyl@yahoo.co.id
}

\begin{abstract}
Abstrak
Since its emergence in $70^{\text {st }}$ MUI has been signaled by some parties as a an institution which is intendedly bias and political-based interest although its founded for solving socio-religious problems. It can be seen from its fluctuative movement. There is a radicalization symptom within the body of this institution after the affiliation of DDII exponents into its organizational structure in 90st. the phenomenon has been strengthen by the affliation of some radical oraganization into Moslem Forum. Besides, its fatwas tend to ignore the plurality of school of thoughts. In this context, using Khaled Abou ElFadhl' theory, MUI is authoritarian because it does not give chance to other arguments particularly in pluralism legal status and Ahmadiayah sect cases.

Sejak kelahirannya di tahun 70-an, MUI disinyalir oleh beberapa pihak sebagai institusi yang cenderung bias dan sarat dengan kepentingan politik meski tujuan awal pendiriannya adalah memberikan solusi atas persoalan sosial-keagamaan. Hal ini terbukti dalam dinamika perjalanan intitusi ulama tersebut yang demikian fluktuatif. Di antaranya dapat dilihat gejala adanya radikalisasi di tubuh MUI ini setelah banyaknya eksponen DDII yang masuk dalam struktur kepengurusan pada tahun 90-an. Hal tersebut semakin kuat pada tahun 1998-an sejak bergabungnya sejumlah organisasi Islam radikal dalam wadah Forum Umat Islam (FUI). Di samping itu, juga dapat dilihat pada fatwa-fatwanya yang cenderung kurang mempertimbangkan pluralitas madzhab dan pemikiran. Dalam konteks inilah, tampaknya jika dilihat dengan teori yang digagas Khaled Abou ElFadhl, bahwa MUI dinilai otoriter karena tidak memberi peluang kepada pendapat lain, seperti dalam kasus pengharaman pluralisme dan sesatnya aliran Ahmadiyah.
\end{abstract}

Kata kunci: radikalisasi, MUI, fatwa, otoriter.

Sejak awal berdirinya pada tanggal $26 \mathrm{Juli}$ 1975 pada acara Musyawarah Nasional ke-1 Majelis Ulama se-Indonesia yang berlangsung dari 21-27 Juli 1975 di balai Senayan Jakarta $^{1}$, Majelis Ulama Indonesia (selanjutnya disebut MUI), mendapat sorotan yang keras. Beberapa tahun sebelum MUI diresmikan oleh Presiden Soeharto, rencana pembentukan organisasi perkumpulan ulama ini dicurigai sebagi upaya pemerintah untuk membatasi gerak kaum muslimin guna men-

\footnotetext{
${ }^{1}$ Mimbar Ulama, no. 240 (Agustus, 1998), h. 10.
}

dukung kepentingan politik pemerintah. Hal ini didasarkan kepada beberapa alasan, pertama, gagasan pembentukan MUI untuk pertama kalinya dimotori oleh unsur pemerintah pada tahun 1970, satu tahun sebelum dilaksanakan pemilihan umum 1971. Asumsi ini mendapat pembenarannya ketika pada tahun 1973, pemerintah mendesak agar keempat partai politik Islam yang ada menghilangkan "sebutan Islam" dan menggabung dalam satu partai Partai Persatuan Pembangunan (PPP). Kedua, umat Islam memberi- 
kan reaksi keras ketika pemerintah mengajukan rancangan undang-undang perkawinan pada tahun 1973, yang dianggap para ulama sebagai "bernuansa" sekuler karena banyak bertentangan dengan hukum Islam. ${ }^{2}$

Tanggapan negatif terus berlanjut beberapa waktu setelah MUI benar-benar dibentuk. Hal itu bisa dicermati dengan sikap Hamka, ketua umum MUI terpilih pertama, yang pada awalnya enggan untuk memangku jabatan tersebut, namun dengan beberapa pertimbangan akhirnya menerimanya.

Dalam perjalanannya, kecurigaan ulama terhadap upaya pemerintah "mengebiri" para ulama benar-benar terbukti. Hal ini misalnya bisa dilihat pada rambu-rambu yang diberikan Soeharto pada sambutan di acara pembukaan. Rambu-rambu dimaksud, di antaranya MUI adalah penerjemah konsep dan aktivitas pembangunan nasional dan daerah kepada rakyat, menggerakkan dan mengarahkan masyarakat untuk membangun, berfungsi sebagai mediator antara pemerintah dan ulama dan tidak bergerak di bidang politik ${ }^{3}$.

"Peringatan" bernuansa politis tersebut bisa dimaknai bahwa tujuan MUI adalah untuk menetralisir ancaman politik umat Islam dan legitimasi kebijakan-kebijakan keagamaan bagi kepentingan penguasa ${ }^{4}$. Hal ini sebagaimana disinggung oleh WB. Hooker, bahwa mulai periode 1975 sampai awal 1990-an, fungsi utama MUI adalah mendukung dan dalam beberapa hal menjustifikasi kebijakan dan program-program pemerintah. Pendapat senada juga disampaikan oleh Mudzhar, bahwa dari sejak berdirinya sampai akhir tahun 1980-an, MUI tidak berdaya menolak tekanan pemerintah yang memintanya untuk melegitimasi kebijakan-kebijakannya. Fenomena ini berujung pada mundurnya Hamka sebagai ketua umum ketika ia menolak permintaan pemerintah un-

\footnotetext{
${ }^{2}$ Atho Mudhar, Fatwa-Fatwa Majelis Ulama Indonesia: Studi Tentang Pemikiran Hukum Islam di Indonesia (Jakarta: INIS, 1993), h. 61-62,

${ }^{3}$ Atho Mudhar, Fatwa-Fatwa., h. 63.

${ }^{4}$ Ahmad Zainul Hamdi, Radikalisasi Islam Melalui Institusi Semi Negara: Studi Kasus atas Peran MUI Pasca Soeharto (Riau: Makalah ACIS, 2007), h. 4.
}

tuk menarik fatwa tentang haramnya umat Islam menghadiri peringatan Natal, meskipun banyak orang melihat mundurnya Hamka dari MUI karena alasan kesehatan ${ }^{5}$.

Di samping itu, ada beberapa contoh yang bisa dimajukan terkait dengan analisis di atas. Salah satu di antaranya adalah kasus penggunaan alat kontrasepsi IUD (Intra Uterine Device) dalam pelaksanaan keluarga berencana (KB). Pada tahun 1971, sekelompok ulama mengeluarkan fatwa bahwa penggunaan IUD untuk KB dihukumi haram, karena pemasangannya dilakukan dengan membuka aurat perempuan. Pemerintah menganggap bahwa fatwa tersebut dapat merugikan program $\mathrm{KB}$, sehingga para ulama dibujuk agar menarik fatwa tersebut. Baru dua belas tahun kemudian pemerintah berhasil membujuk ulama. Pada tahun 1983, dengan dukungan dana dari Departemen Agama dan BKKBN, diadakan konferensi nasional para ulama di Jakarta, di mana akhirnya pelarangan penggunaan IUD benar-benar dicabut ${ }^{6}$. Keberhasilan mencabut fatwa tersebut, lagilagi memperkuat tuduhan bahwa pemerintah telah menggunakan MUI untuk meligitimasi kebijakannya.

Contoh lain yang merupakan kritik terhadap MUI atas ketidak berdayaannya di hadapan pemerintah adalah tentang judi lotere (Porkas) yang disponsori oleh pemerintah untuk menggalang dana olahraga. Sejak awal umat Islam telah memprotes keberadaan lotere tersebut karena dianggap sebagai judi yang diharamkan dalam Islam. Sekalipun demikian MUI hanya terdiam. Bahkan ketua Komisi Fatwa MUI saat itu, Ibrahim Hosein, menjelaskan pandangannya tentang halalnya Porkas. Sekalipun Hosein menyatakan bahwa pernyataannya itu sebagai pendapat pribadi, masyarakat tetap saja menyorotnya sebagai representasi MUI. MUI baru mengeluarkan fatwa bahwa judi lotere (Porkas dan SDSB) adalah haram karena madharatnya lebih besar daripada manfaatnya pada 23 November 1991, setelah para maha-

\footnotetext{
${ }^{5}$ Ahmad Zainul Hamdi, Radikalisasi..., h. 72.

${ }^{6}$ Ahmad Zainul Hamdi, Radikalisasi..., h. 71.
} 
siswa Muslim melakukan demonstrasi. ${ }^{7}$ Dari sini tampak bahwa fatwa-fatwa MUI hanyalah melegitimasi kebijakan pemerintah, baik dilakukan dengan cara mengeluarkan fatwa yang bersifat supportif secara langsung maupun abstain dalam sebuah kasus yang dilematis.

Belum surut kritik yang ditujukan kepada MUI sebagai "alat stempel" pemerintah, MUI sejak tahun 1990-an diduga menjadi tempat gerakan Islam radikal ${ }^{8}$. Tuduhan ini dibuktikan dengan munculnya beberapa fatwa yang memiliki "aroma" sama dengan prinsip-prinsip gerakan "Islam radikal" dan cenderung "menyerang" kelompok Islam tertentu. Fatwa tentang sesatnya aliran Ahmadiyah, dilarangnya paham Syiah dan larangan bagi umat Islam memiliki paham pluralisme, sekularisme dan liberalisme, dapat disebut sebagai eksemplarnya. Fatwa-fatwa tersebut, lebih jauh terasa ekslusif, sepihak dan mengarah kepada sikap otoriter seperti yang disinyalir oleh Khaled Abou El Fad$\mathrm{hl}$ tentang terjadinya otoritarianisme dalam pemikiran hukum Islam. Tulisan ini hendak melihat lebih jauh tentang gejala radikalisme di tubuh MUI, telah berdampak pada otoritarianisme dengan menggunakan kerangka pemikiran Khaled Abou El-Fadhl.

\footnotetext{
${ }^{7}$ Himpunan Fatwa Majelis Ulama Inodnesia (Jakarta: Departemen Agama RI, 2003), h. 209.

${ }^{8}$ Belum ada kesepkatan di antara pengamat Islam tentang istilah yang tepat untuk menggambarkan gerakan radikal. Oliver Roy menyebut gerakan Islam yang berorientasi pada pemberlakuan syari'at sebagai islam fundamentalis. Muhammad Ābid al-Jābiri mengistilahkan dengan ektremisme Islam sebagai bandingan atas Islam moderat. Robert W. Hefner menggunakan istilah islam anti liberal, sedangkan William Lidle menggunakan istilah Islam skriptruralis. Sementara itu, Adam Schwarz dalam bukunya Nation in Waiting: Indoensia Search for Stability menyebutnya sebagai Islam militan. Menurutnya, gerakan ini memiliki cirri (1) menafsirkan Islam secara kaku, (2) bersikap anti Barat dan Agama Semit dan (3) kritis terhadap etnik Cina dan umat Kristen yang secara ekonomi dan politik lebih mapan daripada kelompok Islam militan. Beberapa pandangan tersebut pada dasarnya memiliki prinsip yang sama. Untuk kondisi di Indonesia, baik yang menyebutnya dengan Islam radikal, Islam militant, Fundamentalisme Islam, Islam Skriptiuralis maupun Islam anti liberal, menunjuk kelompok FPI, KISDI dan DDII sebagai contohnya. Khamami Zada, Islam Radikal : Pergulatan Ormas-Ormas Islam Garis Keras di Indonesia (Jakarta: Teraju, 2002), 13-18.
}

\section{Khalid Abou El Fadhl dan Gagasan Pemikirannya}

Khaled M. Abou El Fadl dilahirkan di Kuwait pada tahun 1963, yang kemudian tumbuh kembang menghabiskan masa kanakkanak hingga remaja di Kuwait dan Mesir. ${ }^{9}$ Ayahnya, Medhat Abou El Fadl, adalah seorang ahli hukum Islam, yang menjadi guru pertamanya untuk melawan segala bentuk penindasan, dan ibunya, Afaf El Nimr. ${ }^{10}$

Abou El Fadl dibesarkan dalam lingkungan sosial yang tidak menentu, karena pada tahun 1967, Arab dilanda perang yang berakhir dengan kekalahan. Pada saat yang sama terjadi perkembangan ekstremisme agama di berbagai belahan dunia Muslim. Baik puritanisme maupun Wahabisme, telah mengambil alih posisi dan otoritas keagamaan yang cukup signifikan, setelah sebelumnya sempat mengalami kekosongan akibat maraknya kolonialisme. ${ }^{11}$

Pada usia belasan (kurang lebih 12) tahun, ia telah mampu menghafal seluruh alQur'ân, dan belajar berbagai tradisi dan pemikiran Islam secara luas dan mendalam, dengan "menceburkan" diri untuk "menyantap" beragam teks Islam klasik ${ }^{12}$ Pada saat inilah Abou El Fadl menjadi seorang fundamentalis yang sangat setia memegang ajaran yang diyakininya. Ia sangat menentang keras pemikiran kelompok "inkâr al-sunnah" yang muncul dan menjadi wacana yang cukup santer pada saat itu.

Di antara beberapa karyanya adalah The Authoritative and Authoritarian in Islamic Discourses, yang diterbitkan oleh sebuah pener-

\footnotetext{
${ }^{9}$ Rod Dreher, Inside Islam: A Brave Muslim Speaks, NRO (Online), (http://www.nationalreview.com/ dreher/dreher010802.shtml, diakses tanggal 12 Desember 2006); "About Khaled Abou El Fadl," dalam Scholar of the House (Online), (http://www.scholarofthehouse. org/abdrabelfad.html, diakses 12 Desember 2006); Vincent J. Schodolski, "Islamic Scholar Takes on Fundamentalists," dalam Chicago Tribune (Online), 25 November 2002, (http://www.scholarofthehouse.org/ ischictrib.html, diakses tanggal 12 Desember 2006).

${ }^{10}$ Khaled Abou El Fadl, "Catatan tentang Transformasi," dalam Musyawarah Buku: Menyusuri Keindahan Islam dari Kitab ke Kitab, terj. Abdullah Ali (Jakarta: Serambi, 2002), h. 190.

${ }^{11}$ Khaled Abou El Fadl, "Catatan., h. 90.

${ }^{12}$ Khaled Abou El Fadl, “Catatan., h. 90.
} 
bit Muslim pada tahun 1996. Pada tahun 1997 diterbitkan kembali oleh Dar Taiba (Quill Publisher- di Austin). Dalam edisi bahasa Arab, ditulis dengan judul Al-Istibdâd wa al-Marja'iyyah fi al-Khithâb al-Islamî: Di-

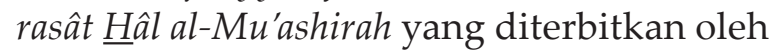
Dar Tuhama. ${ }^{13}$

Speaking in God's Name: Islamic Law, Authority and Women diterbitkan oleh Oneworld Publications, pada tahun 2001. ${ }^{14}$ Tulisan ini selanjutnya direvisi dan menjadi buku baru And God Knows the Soldiers: The Authoritative and Authoritarian in Islamic Discourses.

Masih pada tahun 2001, disertasinya dengan judul Rebellion and Violence In Islamic Law, diterbitkan oleh Cambridge University Press. Tahun 2002 karyanya, The Place of Tolerance in Islam diterbitkan oleh Beacon Press. Karyanya ini merupakan respon kepada serangan terorisme pada 11 Sepetember 2001 yang telah menghancurkan gedung kembar Amerika. ${ }^{15}$ Pada tahun 2003, karyanya yang lain "Islam and the Challenge of Democracy" diterbitkan oleh Princeton University Press. Di antara beberapa karyanya tersebut telah diterjemahkan ke dalam bahasa Indonesia.

\section{Konsep Pemikiran Khalid Abou el Fadhl: Kembali Kepada Tradisi Klasik "Yang Terlupakan"}

Kegelisahan Khalid, seperti dikemukakan di atas, disebabkan oleh tampilan para ahli hukum yang memberikan fatwa secara otoriter. Menurutnya, tradisi klasik yang sangat menghargai pendapat orang lain sudah tidak ditemukan lagi. Hilangnya sikap seperti seperti dinyatakan Abu Hanifah bahwa: "saya yakin bahwa pendapat saya benar, tetapi saya mengakui bahwa pendapat saya mungkin salah, saya juga yakin bahwa pendapat orang lain salah, tapi saya men-

${ }^{13}$ Khaled Abou El Fadl, Speaking in God's Name: Islamic Law, Authority and Women (England: Oneworld Publications, 2003), h. xii.

${ }^{14}$ El Fadl, Melawan., h. 35-37.

${ }^{15}$ Khaled Abou El Fadl, Cita dan Fakta Toleransi dalam Islam: Puritanisme Versus Pluralisme, terj. Heru Prasetia (Bandung: Arasy, 2003), h. 1-19; "The Place of Tolerance in Islam: On reading the Qur'an-and Misreading it," dalam Boston Review (Online), (http://bostonreview.net/ BR27.1/islam.html, diakses 12 Desember 2006). gakui bahwa pendapat mereka mungkin benar,"16 tampaknya tidak ditemukan lagi dalam tradisi intelektualisme Arab. Karena itu pula, sikap Imam Malik yang menolak pendapatnya dijadikan madhab negara karena takut "menjadi otoriter" adalah sebuah contoh yang memperkuat pernyataan di atas. Khalid menyebutnya sebagai "tradisi yang terlupakan". Karena itu, ia menyerukan perlunya mengambil kembali tradisi klasik yang otoritatif.

Lebih lanjut, menurut Abou El Fadl ada perbedaan antara sikap otoriter dengan otoritatif. Otoriter adalah mengikuti sebuah pendapat tanpa mengetahui referensinya (taklid buta) dan menolak pendapat yang berlainan dengannya, sedangkan otoraitatif adalah melakukan pilihan terbaik berdasarkan rasio (subyektifitas yang bertanggung jawab) ${ }^{17}$.

Terdapat beberapa faktor yang menyebabkan fatwa-fatwa hukum cenderung otoriter dan mengabaikan toleransi. Di antaranya adalah sikap seorang interpreter (ahli hukum) yang merasa paling mengetahui kehendak Tuhan. Hal ini, dipicu oleh runtuhnya epistemologi hukum Islam tradisional, sehingga para pemikir hukum Islam modern cenderung untuk sekedar mengadopsi dan memilih salah satu pendapat dari berbagai madhab tanpa menghiraukan integritas epistemologi dari madhab masing-masing. Apalagi, tidak sedikit para pemikir hukum Islam modern adalah para aktivis politik dan sosial yang hanya mengenyam sedikit pendidikan dalam tradisi kesarjanaan Islam. ${ }^{18} \mathrm{Di}$ samping itu, adanya kehancuran pranata sosial akibat kolonialisme dan adaptasi atas sistem civil law di dunia Islam, serta penerapan hukum sekuler yang menyebabkan terkikisnya khazanah hukum Islam, adalah alasan lain yang memperkuat terjadinya otoritarianisme.

\footnotetext{
${ }^{16}$ Subhi Mahmasanī, Falsafat al-Tashri fi al-Islām (Beirut: Dār al-Ilm li al-Malayīn, tt), h. 42.

${ }^{17}$ Khaled Abou El Fadhl, Atas Nama Tuhan: Dari Figh otoriter ke Fiqih Otoritatif terj. Cecp Lukman Yasin (Jakarta: Serambi, 2004), h. 143 dan 204.

${ }^{18}$ Khaled Abou El Fadhl, Atas Nama Tuhan., h. 249. Lihat juga W.B Hallaq, Islamic Legal Theories: An Introduction to Sunni Usūl al-Figh (Cambridge: Cambridge Universiti Press, 1997), h. 207-211.
} 
Lebih lanjut, menurut Abou El Fadl bahwa munculnya otoritarianisme juga tidak bisa dilepaskan dari pengaruh paham wahabisme, sebuah paham yang diintrodusir oleh Muhammad ibn Abd al-Wahhab pada abad ke-18. Paham ini meyakini bahwa umat Islam telah melakukan kesalahan dengan menyimpangkan ajaran Islam yang lurus. Karenanya, kelompok ini menyerukan perlunya kembali kepada Islam murni, yang dicontohkan oleh Rasulullah dan para sahabat. Mereka menentang segala bentuk intelektualisme, mistisisme dan sektarianisme dalam Islam yang dianggapnya sebagai inovasi yang menyimpang dari Islam akibat pengaruh dari luar.

Menurut paham ini, segala bentuk inovasi dan keragaman pemikiran telah menyebabkan terjadinya perpecahan di kalangan umat Islam. Semua ahli hukum yang tidak menggunakan pendekatan literalis dan mengadopsi model-model analisis rasional dalam memahami Islam dianggap telah melakukan bid'ah. Bahkan mereka dituduh sebagai "pengikut setan" (a'wan al-shayatin) dan boleh dijatuhi hukuman mati. Paham wahabisme tidak pernah memberikan toleransi kepada kelompok-kelompok lain yang berseberangan dengannya, sehingga mereka sangat eksklusif. ${ }^{19}$

Kelompok Wahabiyah berhasil menyebarkan pahamnya hampir ke seluruh dunia Islam dan masih eksis sampai sekarang. Hal ini disebabkan oleh keberhasilan mereka untuk menjadi madhab pemerintah Saudi Arabia dan berhasil memegang dua tempat sentral bagi umat Islam, yaitu Mekah dan Madinah. Terlebih lagi, pada tahun 1975 ketika harga minyak dunia mengalami kenaikan, publikasi paham wahabisme yang didukung oleh pemerintah Saudi Arabia menjadi sangat gencar. Pada tahun 1980-an, penyebaran paham ini dilakukan dengan pemberian donasi untuk sekolah-sekolah, penerbitan, organisasi, perorangan dan pendistribusian literatur-literatur wahabisme. ${ }^{20}$

${ }^{19}$ Khaled Abou El Fadhl, Selamatkan Islam dari Muslim Puritan. terj. Helmi Mustofa (Jakarta: Serambi, 2005)..., h. 61-71.

${ }^{20}$ Khaled Abou El Fadhl, Selamatkan..., h. 91.

\section{Negosiasi antara Teks, Pembaca dan Pengarang}

Meski Abou El Fadl tidak pernah secara eksplisit menyebut gagasannya dengan istilah hermeneutika, tetapi kerangka yang dibangunnya mengikuti cara berpikir hermeneutika. Dibanyak tulisannya, ia menyerukan perlunya seorang interpreter menegosiasikan antara teks, pengarang dan pembaca dalam menggali makna nash, karena baik teks, pembaca maupun pengarang memiliki problem masing-masing.

Teks adalah sekelompok entitas yang digunakan sebagai tanda yang dipilih, disusun dan dimaksudkan oleh pengarang dalam konteks tertentu untuk mengantarkan beberapa makna tertentu kepada pembaca. Ia merupakan simbol yang tersusun dari huruf, kata maupun angka yang memiliki makna. Ia memiliki integritas sendiri yang tidak bisa dipaksa sesuai dengan kemauan pembaca (pemberi makna). Semakin keras upaya pembaca menggiring teks, semakin kuat teks menentang pembaca. Jika teks diinterpretasikan melebihi batas yang rasional, mungkin ia tidak hanya akan menolak legitimasi interpretasi pembaca, tetapi teks juga akan menentang kemampuan pembaca dalam melakukan interpretasi ${ }^{21}$. Karenanya, pembaca yang menggali sebuah makna dari sebuah nash harus mempertimbangkan kemauan teks. Di sinilah pentingnya bernegosiasi dengan teks.

Sebagai contoh, nash mengatakan "Tidak ada paksaan dalam agama". Berdasarkan teks tersebut, berarti tidak ada paksaan agama. Tetapi mungkin pembaca akan memberikan pemaknaan: orang yang mau Islam tidak bisa dipaksa untuk mengakui Islam, atau tidak bisa dipaksa melakukan puasa, shalat dan memakai jilbab, orang yang keluar dari Islam (murtad) tidak bisa dihukum, atau boleh membatalkan janji-janji kesetiaan, atau hukuman bagi peminum khamr bisa ditinggalkan karena tidak ada pemaksaan.

Hanya saja, semakin meluas dan menyimpang pemaknaan-pemaknaan ini, semakin kuat teks menentang pembaca, karena teks ${ }^{21}$ Khaled Abou El Fadhl, Atas Nama Tuhan., h. 200201 
tidak memaksudkan untuk persoalan shalat, puasa, kesetiaan dan sebagainya. Dalam konteks ini, komunitas interpretasi dianggap tidak mampu mengendalikan diri. ${ }^{22}$

Seorang pembaca yang tidak berhasil bernegosiasi dengan teks akan terseret ke dalam otoritarianisme (sikap otoriter). Apalagi kondisi seorang pembaca (interpreter) yang berusaha menangkap kehendak Tuhan selalu diliputi oleh beberapa hal yang menjadi problem pembaca yakni "asumsi dasar". Ada empat jenis asumsi dasar yang selalu menjadi landasan untuk membangun analisis hukum, yaitu asumsi berbasis nilai, asumsi metodologis, asumsi berbasis iman, dan asumsi berbasis akal.

Asumsi berbasis nilai dibangun berdasarkan nilai-nilai normatif yang dipandang penting atau mendasar oleh sebuah sistem hukum, seperti prinsip kebebasan berbicara dan pentingnya perlindungan hak milik. Dalam konsep Islam, asumsi ini dapat disetarakan dengan konsep daruriyah. Adapun asumsi metodologis didasarkan pada pendekatan teoretis yang sistematis terhadap hukum. Terjadinya perbedaan pendapat antara berbagai madhab hukum dapat dipandang sangat bersifat metodologis. Dalam praktiknya terjadi tumpang tindih antara asumsi berbasis nilai dengan asumsi metodologi. Sebagai contoh, konsep maslahah yang menyatakan "bahwa kepentingan umum dapat menyimpang dari nash", sulit dipetakan apakah hal itu semata-mata persoalan nilai normatif ataukah persoalan metodologis ${ }^{23}$.

Berbeda dengan dua asumsi di atas, asumsi berbasis akal adalah asumsi yang eksistensinya diperoleh dari logika atau bukti hukum dan bukan sebuah dinamika langsung antara seseorang dengan Tuhannya. Ia mempertimbangkan bukti rasional dan tidak mendasarkan kepada pengalaman etis, eksistensialis atau metafisik yang bersifat pribadi.

Sementara itu, asumsi berbasis iman bersumber dari hubungan antara wakil dan Tuannya. Asumsi ini dibangun atas dasar pemahaman pokok tentang karakteristik pe-

${ }^{22}$ Khaled Abou El Fadhl, Atas Nama Tuhan., h. 199.

${ }^{23}$ Khaled Abou El Fadhl, Atas Nama Tuhan..., h. 229. san Tuhan dan tujuannya, yang membentuk kesadaran dan keyakinan yang tidak bisa dibagi kepada orang lain.

Asumsi-asumsi di atas selalu melekat kepada setiap pembaca ketika menangkap kehendak Tuhan. Karena itu, untuk mengeliminasi munculnya sikap otoriter seorang ahli hukum Islam ketika memahami pesan Tuhan, diperlukan beberapa syarat yaitu kejujuran (honesty), mampu mengendalikan diri (selfrestrain), komprehensif (comprehensive), rasional (reasonable) dan sungguh-sungguh (diligent). Bagi Abou El Fadl, jika seorang interpreter (ahli hukum Islam) memiliki sikap-sikap di atas, otoritarianisme akan mampu dibendung. Dengan lima sikap itu pula, seorang pembaca akan dapat dengan sungguh-sungguh melakukan negosiasi dengan teks. Munculnya kesadaran seseorang terhadap adanya perbedaan asumsi dasar yang mempengaruhi setiap pembaca, menurut Abou El Fadl, akan dapat menjadikan seorang pembaca tersebut tidak bersikap otoriter.

Sementara itu, problem pemaknaan terhadap nash juga terjadi pada pengarang (author) sebagai pembuat teks. Menurut Khaled, selain al-Qur'an, proses kepengarangan selalu melibatkan pertimbangan sosial, politik dan teologi. Karenanya, proses kepengarangan bias terdiri dari pengarang histories, pengarang produksi, pengarang revisi dan pengarang interpretasi ${ }^{24}$.

Jika seorang pembaca mampu menegosiasikan masing-masing komponen, yakni teks, pembaca dan pengarang, maka pembaca tersebut dapat dikatakan otoritatif, sekalipun tidak "kosong" dari subyektifitas. Karena, bagi Abou El Fadl kebenaran tidaklah bertumpu kepada hasil, melainkan kepada upaya yang dilakukan sebagaimana yang dipedomani oleh kelompok Mushawwibah ${ }^{25}$. Dengan kata lain kebenaran bukanlah sama sekali bersifat obyektif, tetapi bersifat subyektif yang bertanggung jawab (inter-subyektifitas).

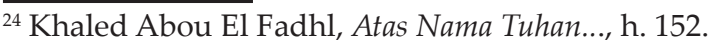

${ }^{25}$ Dalam Islam terdapat 2 aliran dalam memandang kebenaran, yaitu Musawwibah dan Mukhatti'ah.
} 


\section{Radikalisasi MUI}

Munculnya gejala radikalisasi dalam "tubuh" Majelis Ulama Indonesia (MUI) berawal dari tahun 1990-an, ketika Soeharto membangun aliansi dengan kelompok-kelompok Islam yang sebelumnya bermusuhan, misalnya DDII (Dewan Dakwah Islamiyah Indonesia), dalam rangka membendung gerakan-gerakan pro-demokrasi dan kekuatan-kekuatan kritis lainnya. Pergeseran dan perubahan orientasi politik rezim yang berkuasa pada saat itu memiliki konsekuensi pada perubahan di dalam MUI. Hal ini terlihat pada kepengurusan MUI periode 1995-2000 yang mulai memasukkan tokohtokoh penting DDII, termasuk Anwar Haryono dan Hussein Umar, ketua dan sekretaris DDII. Bahkan Hussein Umar diangkat sebagai staf ahli dalam Musyawarah Nasional MUI ke-5 pada 22-25 Juli $1995 .{ }^{26}$ Hal penting yang dapat dicatat dari peristiwa tersebut adalah bahwa selama ini MUI tertutup bagi tokoh-tokoh DDII yang dianggap sebagai kelompok Islam ekstrem yang tidak mendapat tempat dalam kehidupan politik Orde Baru.

Tanpa disadari, sejak saat itu sikap MUI seringkali tidak berbeda dengan sikap keislaman kalangan konservatif. Sebagai contoh, ketika terjadi peristiwa "Kudatuli" (kerusuhan 27 Juli), di mana pemerintah menuduh PKI berada di belakangnya, kelompok Islam konservatif dengan bersemangat membela pemerintah. Dalam beberapa edisi, Media Dakwah, media DDII, melaporkan bahwa mimbar bebas yang dilakukan di kantor pusat DPP PDI berlangsung sangat brutal seperti perilaku PKI. Edisi bulan berikutnya, Agustus 1996, media tersebut menurunkan laporan bahwa PKI menunggang $\mathrm{PDI}^{27}$.

Menyikapi peristiwa di atas, MUI secara kelembagaan mengeluarkan pernyataan resmi bahwa kekuatan komunis berada di belakang aksi kerusuhan. Pada saat yang sama MUI juga bersikap membenarkan tindakan yang dilakukan aparat keamanan dalam menghadapi peristiwa tersebut.

\footnotetext{
${ }^{26}$ Media Dakwah (Agustus, 1995)..., h. 12.

${ }^{27}$ Media Dakwah (Agustus, 1996)..., h. 45-46.
}

Di samping itu, MUI bersama ormas Islam lain juga membuat pernyataan atas nama 'Sikap Umat Islam". Salah satu isi dari pernyataan tersebut adalah menyerukan agar umat Islam dan generasi muda waspada terhadap bahaya laten komunis, dan menyerukan kepada umat beragama agar tidak menjadikan rumah ibadah sebagai persembunyian oknum-oknum PRD dan aktor intelektualnya. ${ }^{28}$

Pada tahun 1998, menjelang jatuhnya Soeharto, faksi konservatif di tubuh MUI semakin menguat. Hal ini terjadi sejak Din Samsudin yang saat itu menjadi sekretaris harian MUI, membawa beberapa organisasi Islam radikal seperti Forum Komunikasi Ahlussunah Wal Jamaah (FKAWI), Hizbut Tahrir (HT) dan Front Pembela Islam (FPI) ke dalam MUI, melalui pintu Forum Ukhuwah Islamiyah (FUI). Menurut Din, sikap yang demikian ini diambil dalam rangka berupaya menjembatani gap antara kelompok muslim radikal dan muslim moderat.

Hal lain yang penting untuk dicatat adalah bahwa FUI yang menjadi pintu masuk Islam radikal ke dalam MUI adalah forum bersama organisasi dakwah (orda) dan organisasi masyarakat (ormas) Islam yang selama ini terkoordinasi di bawah payung DDII. Artinya, FUI yang pendiriannya dilatarbelakangi oleh keprihatinan atas kristenisasi yang terjadi selama Orde Baru, memiliki keterkaitan yang erat dengan DDII.

Kedekatan FUI dengan DDII juga bisa dilihat dari susunan presidiumnya. Setelah disahkan pada 18 Februari 1995, presidium FUI beranggotakan sembilan orang yang terdiri dari pimpinan puncak ormas-ormas Islam antara lain Ittihadul Muballighin, Muhamadiyah, DDII, PUI, al-Irsyad al-Islamiyah, BKSPPPI (Badan Kerjasama Pondok Pesantren Indonesia, Persis dan SI (Sarikat Islam) ${ }^{29}$. Jadi FUI adalah front bersama perjuangan politik ormas-ormas Islam yang memiliki kedekatan dan bahkan kesamaan ide-

\footnotetext{
${ }^{28}$ Lihat "Sikap Umat Islam", dalam Mimbar Ulama no. 216 tahun xx (Agustus, 1996)..., h. 11-12.

${ }^{29}$ AM. Lutfi, "Kita Ada PAda Titik Belok Perjalanan Bangsa" dalam Media Dakwah (Juli, 1998)..., h. 51.
} 
ologis dengan keluarga besar DDII. Bahkan bisa dikatakan bahwa DDII menjadi unsur dominan di dalam tubuh FUI.

Lebih lanjut, kelompok konservatif ini memiliki pengaruh yang kuat di dalam MUI. Ali Yafie, ketua umum MUI dari tahun 19982000, menyatakan bahwa FUI adalah pendamping MUI. Dia juga menyatakan bahwa FUI berperan aktif dari saat berkembangnya reformasi, terutama bulan Mei, saat Soeharto mengundurkan diri. Forum ini juga melakukan pertemuan dan arahan serta bimbingan kepada umat Islam secara terus menerus sesuai dengan peran MUI. ${ }^{30}$ Pengakuan MUI terhadap FUI sebagai forum pendampingnya ini dibuktikan dengan mengikutsertakan FUI untuk menyikapi problem-problem nasional, sehingga FUI turut berpartisipasi dalam pengeluaran statemen-statemen yang diberikan oleh MUI.

Penjelasan di atas, menunjukkan bahwa FUI memiliki pengaruh yang sangat kuat terhadap MUI. Kuatnya pengaruh FUI terhadap MUI juga berarti menguatnya pengaruh kalangan muslim radikal terhadap MUI. Oleh karena itu, munculnya beberapa fatwa MUI belakangan, seperti haramnya pluralisme dan sesatnya Ahmadiyah, juga tidak bisa dilepaskan dari pengaruh karakter kelompok koservatif yang ada di MUI. Hal ini juga sekaligus memperkuat dugaan adanya radikalisasi di MUI.

\section{Membaca Otoritarianisme MUI dengan Pemikiran Abou El Fadl: Kasus Fatwa Tentang Aliran Ahmadiyah}

Salah satu fatwa MUI yang dikaitkan dengan gejala radikalisme adalah fatwa tentang sesatnya aliran Ahmadiyah, yang mempertegas fatwa sebelumnya tentang pencegahan penyusupan gerakan Ahmadiyah ke Indonesia tahun 1984. Fatwa ini telah menimbulkan polemik yang berkepanjangan, yang menjurus kepada tindakan destruktif. Beberapa tempat yang diduga menjadi basis gerakan Ahmadiyah dihancurkan. Pengikut gerakan ini bahkan dimusuhi oleh kelompok tertentu dalam Islam, dengan merujuk kepada fat-

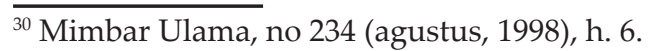

wa tersebut.

Ada tiga alasan yang menjadi pijakan MUI untuk menyatakan kesesatan Ahmadiyah, yaitu pengakuan Mirza Ghulam Ahmad sebagai Nabi terakhir, kepemilikan kitab suci al-Qur'an yang disebut tazkirah dan arah ka'bah selain Masjidil Haram. ${ }^{31}$ Lebih lanjut, menurut MUI keyakinan Ahmadiyah tersebut bertentangan dengan hal yang prinsip dalam agama, yang bisa mengantar pengikutnya menjadi kafir.

Satu hal yang perlu dicatat terkait dengan alasan MUI di atas, yaitu apakah fatwa tersebut "satu-satunya" pendapat yang disepakati umat Islam? Karena, bagi kalangan Ahmadiyah sendiri, alasan MUI dinilai berbeda dengan yang dipahaminya, bahkan dinyatakan bahwa tuduhan tersebut diklaim MUI salah alamat.

Menurut paham di kalangan Ahmadiyah, bahwa mereka meyakini seluruh Rasul dan Nabi, baik yang disebutkan dalam al-Qur'an maupun tidak. Ahmadiyah tetap mengakui Muhammad sebagai Nabi terakhir dan junjungan paling utama dari seluruh Nabi dan Rasul tersebut. Menurut mereka, adanya konsep kenabian setelah Muhammad tetap saja tidak mengurangi kemulyaan Nabi Muhammad. ${ }^{32}$

Ahmadiyah berpendapat bahwa wahyu tanpa syari'at akan turun terus menerus tiada hentinya. Untuk memahami makna khatam al-Nabiyyin ${ }^{33}$, Ahmadiyah membedakan dua konsep kenabian, yaitu kenabian yang membawa syari'at (Nabi Tashri') dan kenabian yang tidak membawa syari'at, atau yang disebut Nabi Ummat ${ }^{34}$. Menurut mereka, Nabi Muhammad merupakan Nabi Tashrī' yang tidak akan ada Nabi lagi setelahnya yang membawa syari'at baru dari Tuhan. Adapun Mirza Ghulam Ahmad merupakan Nabi Ummatī yang bertugas sebagai pembaharu (mujaddid) dari shari'ah yang dibawa Nabi Muhammad sebagaimana Isa al-Masih

\footnotetext{
31 "Laporan Khusus Sebelas Fatwa MUI", dalam Gatra (6 Agustus 2005), h. 77.

${ }^{32}$ Aksin Wijaya,"Mendiskursuskan Kembali Konsep Kenabian", Al-Tahrir, 5 No. 2 (2005)..., h. 124.

${ }^{33}$ Al-Qur'an: al-Ahzāb..., h. 40.

${ }^{34}$ Aksin Wijaya,"Mendiskursuskan..., h. 125.
} 
yang akan hadir membela ajaran Nabi Muhammad di kemudian hari.

Berkaitan dengan anggapan bahwa persoalan kenabian adalah hal yang prinsip ( $u \underline{s} \bar{u} l)$ yang dirumuskan ke dalam rukun Iman dan rukun Islam, Ahmadiyah menilainya sebagai furu'. Perbedaan paham seperti ini sesungguhnya telah terjadi sejak lama, bahkan perbedaan untuk menentukan apa yang dikategorikan sebagai hal yang pokok dan hal yang tidak pokok. Di kalangan pemikir muslim klasik, khususnya para teolog, juga telah ada perbedaan pendapat mengenai soal ini.

Jika 'Ash'ariyah merumuskan rukun Iman dan rukun Islam, Mu'tazilah, seper-

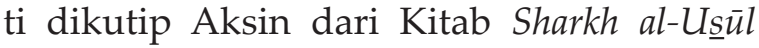
al-Khamsah, menganggap bahwa yang prinsip adalah keyakinan terhadap lima dasar (Usiūl al-Khamsah) yaitu Tawhid, al-Adl, alWa'd wa al-Wa'ìd, al-Manzil bayna al-Manzilatayn dan Amar Ma'ruf wa Nahy an al-Munkar. ${ }^{35}$ Al-Ghazalī menganggap bahwa pengetahuan Tuhan, keabadian alam dan kebangkitan jasad di hari akhir merupakan hal yang prinsip dalam agama, sedangkan Ibn Rusyd memahami bahwa yang prinsip dalam agama adalah menyangkut Allah, Nabi dan Hari Akhir. Begitu juga al-Qur'an, menggunakan redaksi yang beragam dalam menjelaskan persoalan $u \underline{s} \bar{u} l$ tersebut. ${ }^{36}$

Berdasarkan uraian di atas, tampak adanya beragam pendapat terkait dengan rujukan yang digunakan MUI dalam membuat fatwa tentang Ahmadiyah. Dengan model pemikiran Khaled Abou El Fadhl, fat${ }^{35}$ Aksin Wijaya,"Mendiskursuskan., h. 129.

36 Terlepas dari perbedaan Mufassir dalam memahami ayat yang beragam, al-Qur'an menggunakan redaksi yang berbeda ketika menjelaskan persoalan Iman. Al-Baqarah: 62 menjelaskan tentang keharusan Iman kepada Allah dan hari Akhir, al-Baqarah: 285 tentang beriman kepada Allah, Malaikat-Nya, Kitab-Nya dan Rasul-Nya, dan al-Baqarah: 177 menjelaskan tentang beriman kepada Allah, hari Akhir, Malaikat, Kitab dan Nabi.

\section{DAFTAR PUSTAKA}

Abd al-Jabar, Ahmad. tt. Sharkh al-Ușūl alKhamsah. Mesir: Wahba Library.

Hamdi, Ahmad Zainul. 2007. Radikalisasi Islam Melalui Institusi Semi Negara: Stu- wa MUI bisa disebut sebagai otoriter. Beberapa alasan dapat dikemukakan dalam menjelaskan persoalan ini. Pertama, fatwa MUI yang hanya memegangi satu pendapat "tanpa" menjelaskan pendapat yang lain, bisa dikatakan bahwa MUI tidak "jujur" dan "komprehensif" -dua dari lima syarat yang diharuskan oleh Abou El Fadhl dalam memutuskan sebuah hukum. Kedua, terdapat asumsi berbasis iman yang sangat mendominasi pada lembaga ini. Munculnya gejala radikalisasi yang ada di MUI yang berdampak pada otoritarianisme fatwa seperti uraian di atas menjadi relevan untuk menjelaskan hal ini. Kuatnya asumsi berbasis iman yang ada di MUI tidak bisa dilepaskan dengan pergeseran pemikiran yang ada di dalamnya. Meski tidak menyebut sebagai kesalahan, bagi Abou El Fadhl semestinya MUI menjelaskan pilihannya itu tanpa menyalahkan yang lain "sesat".

\section{Kesimpulan}

MUI merupakan institusi ulama yang semestinya melahirkan fatwa-fatwa yang otoritatif. Namun, tidak dapat dipungkiri bahwa dalam tubuh MUI sendiri juga terdapat sejumlah friksi, yang kemudian mempengaruhi pada fatwanya, sehingga jika diklasifikasikan ada yang tergolong netral, namun ada yang cenderung bias kepentingan politik-pemerintahan. Disamping itu, masuknya sejumlah eksponen gerakan Islam radikal sejak tahun 90-an dan puncaknya pada tahun 1998 ketika masuknya sejumlah unsur Islam garis keras yang tergabung dalam Forum Umat Islam (FUI), berimbas pada fatwa-fatwa yang dikeluarkan oleh intitusi ulama tersebut. Jika dianlisis dari teori khaled Abou el fadhal, maka terdapat sejumlah fatwa MUI yang cenderung menunjukkan adanya otoritarianisme, karena kurang memberikan ruang dan pilihan bagi pendapat lain.

di Kasus atas Peran MUI Pasca Soeharto. Riau: Makalah ACIS.

Wijaya, Aksin. 2005. "Mendiskursuskan Kembali Konsep Kenabian", Al-Tahrir. 
5 No.

Mudhar, Atho. 1993. Fatwa-Fatwa Majelis Ulama Indonesia: Studi Tentang Pemikiran Hukum Islam di Indonesia. Jakarta: INIS.

Himpunan Fatwa Majelis Ulama Inodnesia. 2003. Jakarta: Departemen Agama RI.

El Fadhl, Khaled Abou. 2005. Selamatkan Islam dari Muslim Puritan. terj. Helmi Mustofa. Jakarta: Serambi.

2002. "Catatan tentang Transformasi," dalam Musyawarah Buku: Menyusuri Keindahan Islam dari Kitab ke Kitab, terj. Abdullah Ali. Jakarta: Serambi.

2003. Cita dan Fakta Toleransi dalam Islam: Puritanisme Versus Pluralisme, terj. Heru Prasetia. Bandung: Arasy.
-------. 2004. Atas Nama Tuhan: Dari Figh Otoriter ke Fikih Otoritatif. terj. Cecep Lukman Yasin. Jakarta: Serambi.

Zada, Khamami. 2002. Islam Radikal : Pergulatan Ormas-Ormas Islam Garis Keras di Indonesia. Jakarta: Teraju.

Media Dakwah (Agustus, 1995).

Media Dakwah (Agustus, 1996).

Mimbar Ulama, no 234 (Agustus, 1998).

Mimbar Ulama, no. 240 (Agustus, 1998).

Mahmasanī, Subhi. tt. Falsafat al-Tashri fi alIslām (Beirut: Dār al-Ilm li al-Malayin.

Hallaq, W.B. 1997. Islamic Legal Theories: An Introduction to Sunni Usūul al-Figh. Cambridge Universiti Press. 